\title{
Optimal Design of Air Compressor-Driving Quadratic Linear Actuator in Fuel Cell BOP System Using Orthogonal Arrays Matrix
}

\author{
Jae-Hee Kim ${ }^{1}$, Jin-Ho Kim ${ }^{1}$, and Chang Hwan Jang ${ }^{2}$ \\ ${ }^{1}$ School of Mechanical Engineering, Yeungnam University, Gyeongsan 214-1, Gyeongbuk, Korea \\ ${ }^{2}$ Department of Civil and Environmental Engineering, Kookmin University, Seoul, Korea
}

(Received 12 April 2011, Received in final form 14 June 2011, Accepted 18 June 2011)

\begin{abstract}
The design of an air compressor-driving quadratic linear actuator in a fuel cell BOP system is studied using orthogonal techniques. The approach utilizes an orthogonal array for design of 'experiments', i.e. the scheme for numerical simulations using a finite element method. Eco-friendly energy is increasingly important due to the depletion of fossil fuels and environmental pollution. Among the new energy sources, fuel cell is spotlighted as renewable energy because it produces few dusts. The air compressor performance is directly related to the efficiency of the fuel cell BOP system has high power consumption. In this paper, an optimized technique using an orthogonal matrix is applied to the design problem to improve the performance of quadratic linear actuator.
\end{abstract}

Keywords : fuel cell, BOP system, air Blower, BOP system, linear actuator, orthogonal matrix

\section{Introduction}

The energy industry has been moving toward eco-friendly energy alternatives because of global warming and limited coal resources. Consequently, solar power, wind power, and fuel cell have been researched extensively as alternative new energy sources. Among these new energy sources, the fuel cell is spotlighted renewable energy. A fuel cell has many advantages: low amounts of dust particles $\mathrm{NO}_{\mathrm{X}}$ and $\mathrm{SO}_{\mathrm{X}}$, and lower $\mathrm{CO}_{2}$ production than that by thermal power generation. Generally, a fuel cell system is comprised of a stack and Balance of Plant (BOP).

The compressor in an air blower is a core component of the BOP system, because it requires the largest power consumption. Reciprocating and rotary type driving systems have been established for the air blower compressor. Compared to a rotary type compressor, a linear compressor and a reciprocating compressor particularly have high compressor efficiency because they do not need a motion conversion mechanism and sideways thrust. To make a linear actuator, a number of design factors such as the magnet size, coil turn and yoke size must be considered by time-consuming experiments. Orthogonal arrays are utilized to solve formulated problems. A number of

*Corresponding author: Tel: +82-53-810-2441

Fax: +82-53-810-4627, e-mail: jinho@ynu.ac.kr standard orthogonal arrays have been constructed to facilitate experimental design. Each of these arrays can be used to design experiments to suit various experimental situations. This method can significantly decrease the number of function evaluations $[1,2]$.

To analyze the performance of an electromagnetic linear actuator, a simulation is performed by FEM. FEM (finite element method) is the most effective program for interpreting linear actuator performance. In addition, experimental results are verified by ANOVA (analysis of variance). ANOVA is a statistical data treatment used to sort the relative influences of factors in the results. ANOVA statistics are needed for determining the confidence limits $[3,4]$. This paper aims to design the optimal air compressor-driving linear actuator using the orthogonal matrix.

\section{Orthogonal Array Matrix}

Fig. 1 shows the schematic diagram of a quadratic electromagnetic linear actuator with two pairs of permanent magnets which provide the elevated magnetic field density [5]. As shown in Fig. 1, a linear actuator consists of a coil, coil housing, piston, yoke and magnet. The coil with coil housing is actuated by the oscillating current and the compressor-driving actuator is driven by Lorentz force, as shown as Fig. 2.

For the optimal design of the quadratic linear actuator, 


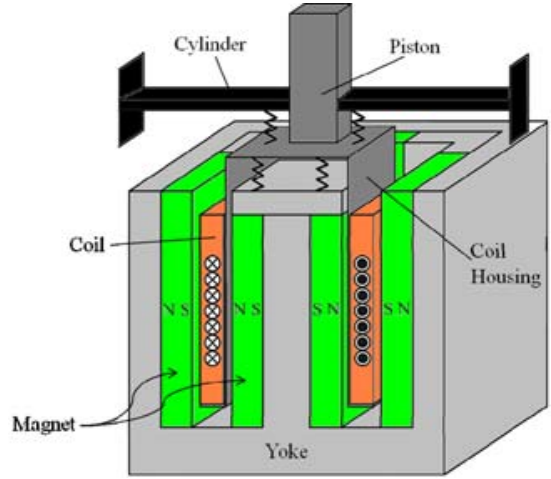

Fig. 1. Schematic diagram of compressor-driving quadratic electromagnetic linear actuator.

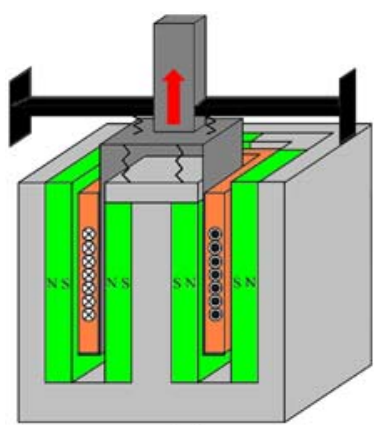

(a)

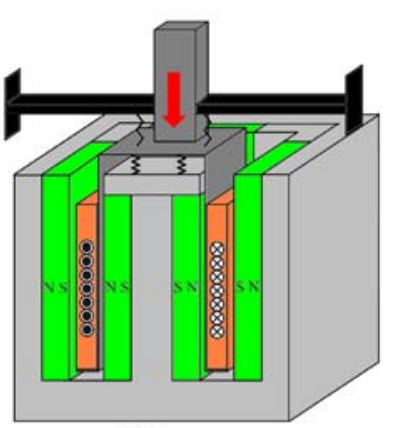

(b)
Fig. 2. Principle of operation (a) at the upper position (b) at lower position.

control factors affecting the Lorentz force are determined because the Lorentz force has the controlling force of the linear actuator. Fig. 3 shows the control factors: the inner magnet (A), the height of upper yoke (B), the thickness of outer magnet $(C)$ and the thickness of lower yoke (D). The levels of control factors and signal factors are shown respectively in Table 1 . The initial actuator design values are designated as $A_{2}, B_{2}, C_{2}$ and $D_{2}$. The full size of the linear actuator and air gap is fixed. The number of coil turn is 250. The constraint of each factor is given in

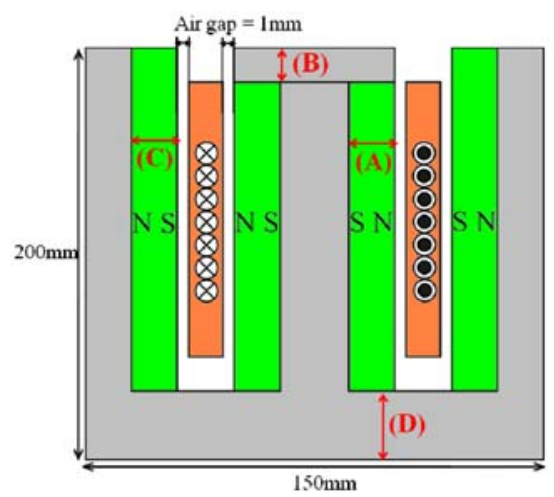

Fig. 3. Control factors of Orthogonal array matrix
Table 1. Control factors and signal factors.

\begin{tabular}{|c|c|c|c|c|c|}
\hline & Indication & Name & 1Level & 2Level & 3Level \\
\hline \multirow{8}{*}{$\begin{array}{c}\text { Control } \\
\text { Factor }\end{array}$} & \multirow{2}{*}{ A } & Thickness of & 12.5 & 15 & 17.5 \\
\hline & & inner magnet & $\mathrm{mm}$ & $\mathrm{mm}$ & $\mathrm{mm}$ \\
\hline & \multirow{2}{*}{ B } & Height of & 6.75 & 8.5 & 10.25 \\
\hline & & upper yoke & $\mathrm{mm}$ & $\mathrm{mm}$ & $\mathrm{mm}$ \\
\hline & \multirow{2}{*}{$\mathrm{C}$} & Thickness of & 11.25 & 12.5 & 13.75 \\
\hline & & outer magnet & $\mathrm{mm}$ & $\mathrm{mm}$ & $\mathrm{mm}$ \\
\hline & \multirow{2}{*}{$\mathrm{D}$} & Thickness of & 15.75 & 21.5 & 27.25 \\
\hline & & lower yoke & $\mathrm{mm}$ & $\mathrm{mm}$ & $\mathrm{mm}$ \\
\hline $\begin{array}{l}\text { Signal } \\
\text { factor }\end{array}$ & M & Current & & $35 \mathrm{~A}$ & \\
\hline
\end{tabular}

Table 2. Constraint factor.

\begin{tabular}{ccc}
\hline \hline & Indication & Constraints \\
\hline & A & $10 \mathrm{~mm} \sim 20 \mathrm{~mm}$ \\
Control & B & $5 \mathrm{~mm} \sim 12 \mathrm{~mm}$ \\
factor & C & $10 \mathrm{~mm} \sim 15 \mathrm{~mm}$ \\
& D & $10 \mathrm{~mm} \sim 33 \mathrm{~mm}$ \\
\hline
\end{tabular}

Table 2.

In this paper, the $\mathrm{L}_{9}(3,4)$ orthogonal array was constructed to derive the optimal condition by 9 experiments. The orthogonal arrays consist of factors with 3 levels and experiments are performed nine times by FEM as shown Table 3. The force of the linear actuator is analyzed by simulation with a commercial electromagnetic analysis software program "MAXWELL". Fig. 4 shows the magnetic density of the linear actuator and Fig. 5 shows the magnetic flux line of the linear actuator.

The experimental force for each case was obtained by FEM. As a result, the main effects for the means of each level are as shown in Fig. 6.

From Fig. 6, the factors $\mathrm{B}$ and $\mathrm{C}$ do not affect the performance greatly. The mean of factor A was chosen as level 3, that of the factor B as level 3, that of factor $C$ as level 3 and that of factor D as level 3 from the main
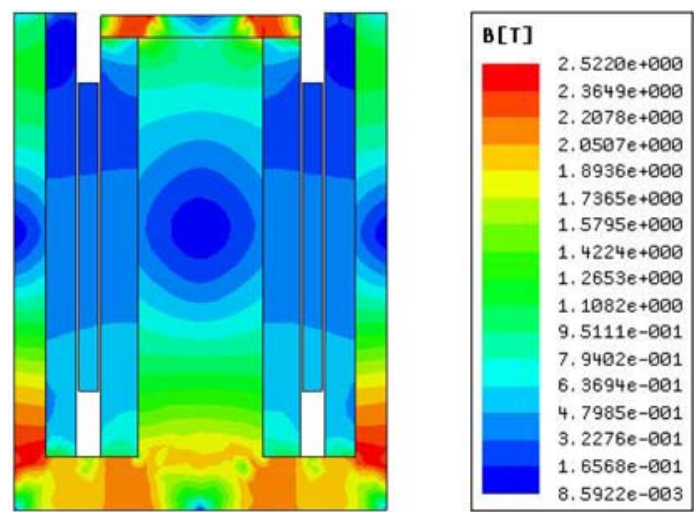

Fig. 4. Magnetic flux density of linear actuator. 


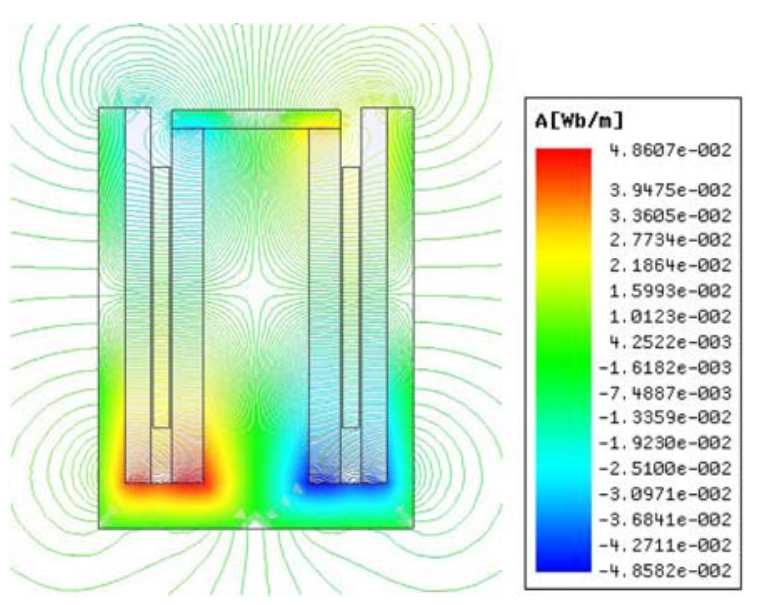

Fig. 5. Flux line of linear actuator.

Table 3. FEM simulation results of each numbers experiment.

\begin{tabular}{cccccc}
\hline \hline & \multicolumn{3}{c}{ Inner array } & \multicolumn{2}{c}{ Outer array } \\
\cline { 2 - 6 } & A & B & C & D & $35 \mathrm{~A}$ \\
\hline 1 & 1 & 1 & 1 & 1 & $5680.6 \mathrm{~N}$ \\
2 & 1 & 2 & 2 & 2 & $6537.3 \mathrm{~N}$ \\
3 & 1 & 3 & 3 & 3 & $7064.8 \mathrm{~N}$ \\
4 & 2 & 1 & 2 & 3 & $7071.9 \mathrm{~N}$ \\
5 & 2 & 2 & 3 & 1 & $6022.1 \mathrm{~N}$ \\
6 & 2 & 3 & 1 & 2 & $6944.8 \mathrm{~N}$ \\
7 & 3 & 1 & 3 & 2 & $6985.5 \mathrm{~N}$ \\
8 & 3 & 2 & 1 & 3 & $7381.1 \mathrm{~N}$ \\
9 & 3 & 3 & 2 & 1 & $6360.9 \mathrm{~N}$ \\
\hline
\end{tabular}

effects plot, so the optimal design is $\mathrm{A}_{3} \mathrm{~B}_{3} \mathrm{C}_{3} \mathrm{D}_{3}$. However, it is not still the maximum value in the constraint range. The maximum performance of the actuator, therefore, needs to be redesigned. The configuration of the second orthogonal array matrix is given in Table 4. Table 5 shows the results of the second FEM simulation by each number of the experiment. From the FEM result, the main effects plot for the mean of each level is shown in Fig. 7.

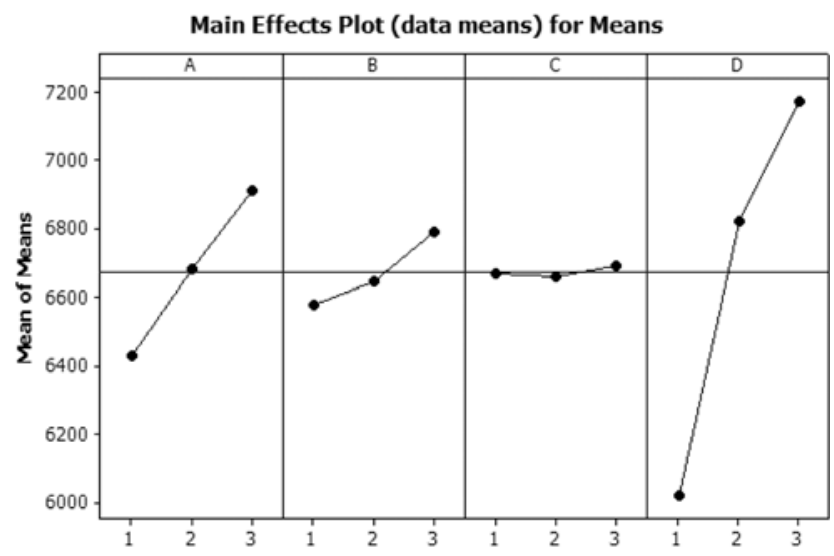

Fig. 6. Main effects plot for means of each level.
Table 4. Configuration of second orthogonal array matrix.

\begin{tabular}{|c|c|c|c|c|c|}
\hline & Indication & Name & 1Level & 2Level & 3Level \\
\hline \multirow{4}{*}{$\begin{array}{l}\text { Control } \\
\text { Factor }\end{array}$} & A & $\begin{array}{l}\text { Thickness of } \\
\text { inner magnet }\end{array}$ & $\begin{array}{l}17.5 \\
\mathrm{~mm}\end{array}$ & $\begin{array}{l}18.75 \\
\mathrm{~mm}\end{array}$ & $\begin{array}{c}20 \\
\mathrm{~mm}\end{array}$ \\
\hline & B & $\begin{array}{l}\text { Height of } \\
\text { upper yoke }\end{array}$ & $\begin{array}{l}10.25 \\
\mathrm{~mm}\end{array}$ & $\begin{array}{c}11.12 \\
\mathrm{~mm}\end{array}$ & $\begin{array}{c}12 \\
\mathrm{~mm}\end{array}$ \\
\hline & $\mathrm{C}$ & $\begin{array}{l}\text { Thickness of } \\
\text { outer magnet }\end{array}$ & $\begin{array}{c}13.75 \\
\mathrm{~mm}\end{array}$ & $\begin{array}{l}14.37 \\
\mathrm{~mm}\end{array}$ & $\begin{array}{c}15 \\
\mathrm{~mm}\end{array}$ \\
\hline & $\mathrm{D}$ & $\begin{array}{l}\text { Thickness of } \\
\text { lower yoke }\end{array}$ & $\begin{array}{c}27.25 \\
\mathrm{~mm}\end{array}$ & $\begin{array}{l}30.12 \\
\mathrm{~mm}\end{array}$ & $\begin{array}{l}33 \\
\mathrm{~mm}\end{array}$ \\
\hline $\begin{array}{l}\text { Signal } \\
\text { factor }\end{array}$ & M & Current & & $35 \mathrm{~A}$ & \\
\hline
\end{tabular}

Table 5. Second FEM simulation results by experiment number

\begin{tabular}{cccccc}
\hline \hline & \multicolumn{4}{c}{ Inner array } & Outer array \\
\cline { 2 - 6 } & A & B & C & D & $35 \mathrm{~A}$ \\
\hline 1 & 1 & 1 & 1 & 1 & $7447.4 \mathrm{~N}$ \\
2 & 1 & 2 & 2 & 2 & $7655.5 \mathrm{~N}$ \\
3 & 1 & 3 & 3 & 3 & $7849.7 \mathrm{~N}$ \\
4 & 2 & 1 & 2 & 3 & $7773.6 \mathrm{~N}$ \\
5 & 2 & 2 & 3 & 1 & $7509.6 \mathrm{~N}$ \\
6 & 2 & 3 & 1 & 2 & $7796.5 \mathrm{~N}$ \\
7 & 3 & 1 & 3 & 2 & $7583.5 \mathrm{~N}$ \\
8 & 3 & 2 & 1 & 3 & $7859.7 \mathrm{~N}$ \\
9 & 3 & 3 & 2 & 1 & $7618.3 \mathrm{~N}$ \\
\hline
\end{tabular}

From Fig. 7, the factors $\mathrm{A}$ and $\mathrm{C}$ do not affect the performance greatly. The mean of factor $\mathrm{A}$ is chosen as level 2, that of factor B as level 3, that of factor $\mathrm{C}$ as level 1 and that of factor $\mathrm{D}$ as level 3 from the main effects plot. The optimal design is $\mathrm{A}_{2} \mathrm{~B}_{3} \mathrm{C}_{1} \mathrm{D}_{3}$. The factor $\mathrm{A}$, the factor $\mathrm{B}$ and the factor $\mathrm{D}$ are the maximum value in the constraint range, but the factor $\mathrm{C}$ is not still the maximum value. The actuator, therefore, needs to be redesigned by the factor $\mathrm{C}$ with other factors fixed. The configuration of the third orthogonal array matrix is given in Table 6 . Table 7 shows the results of the third FEM simulation by

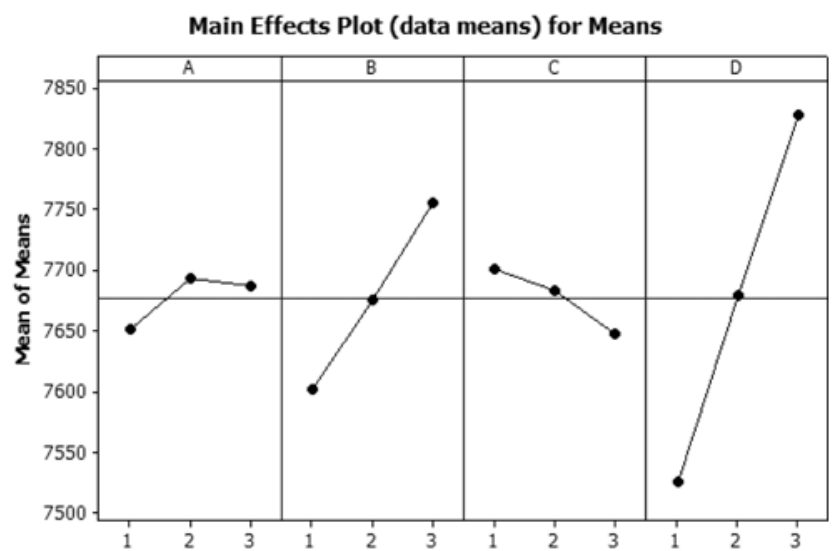

Fig. 7. Main effects plot for means. 
Table 6. Configuration of third orthogonal array matrix.

\begin{tabular}{|c|c|c|c|c|c|}
\hline & Indication & Name & 1Level & 2Level & 3Level \\
\hline \multirow{4}{*}{$\begin{array}{l}\text { Control } \\
\text { Factor }\end{array}$} & A & $\begin{array}{l}\text { Thickness of } \\
\text { inner magnet }\end{array}$ & & $\begin{array}{c}18.75 \\
\mathrm{~mm}\end{array}$ & \multirow{4}{*}{$\begin{array}{c}15 \\
\mathrm{~mm}\end{array}$} \\
\hline & B & $\begin{array}{l}\text { Height of } \\
\text { upper yoke }\end{array}$ & \multirow{3}{*}{$\begin{array}{c}10 \\
\mathrm{~mm}\end{array}$} & $\begin{array}{c}12 \\
\mathrm{~mm}\end{array}$ & \\
\hline & C & $\begin{array}{l}\text { Thickness of } \\
\text { outer magnet }\end{array}$ & & $\begin{array}{c}11.25 \\
\mathrm{~mm}\end{array}$ & \\
\hline & D & $\begin{array}{l}\text { Thickness of } \\
\text { lower yoke }\end{array}$ & & $\begin{array}{c}33 \\
\mathrm{~mm}\end{array}$ & \\
\hline $\begin{array}{l}\text { Signal } \\
\text { factor }\end{array}$ & M & Current & & $35 \mathrm{~A}$ & \\
\hline
\end{tabular}

Table 7. third FEM simulation results by experiment number.

\begin{tabular}{cccccc}
\hline \hline & \multicolumn{4}{c}{ Inner array } & Outer array \\
\cline { 2 - 6 } & A & B & C & D & $35 \mathrm{~A}$ \\
\hline 1 & 2 & 3 & 1 & 3 & $8116.3 \mathrm{~N}$ \\
2 & 2 & 3 & 2 & 2 & $8040.4 \mathrm{~N}$ \\
3 & 2 & 3 & 3 & 3 & $7944.4 \mathrm{~N}$ \\
\hline
\end{tabular}

each number of the experiment. Using ANOVA, the results of the second orthogonal experiments were verified as shown in Table 7.

The factor $\mathrm{C}$ was chosen as the level 1 in Table 1. The optimal design is $\mathrm{A}_{2} \mathrm{~B}_{3} \mathrm{C}_{1} \mathrm{D}_{3}$ which satisfies the maximum value in the constraint range. Using ANOVA, the results of the orthogonal experiments were verified as shown in Table 8.

In Table 8, DF means the detgree of freedom; Seq means the sequential sums of squares; Adj SS means the adjusted sums of squares; and Adj MS means the adjusted mean squares. In the statistical significance testing, the pvalue is the probability of obtaining a test statistic at least as extreme as the one that was actually observed. Therefore, the factor B has $91.8 \%$ reliability, factor $\mathrm{C}$ has $59.5 \%$ reliability and factor D has $97.8 \%$ reliability. The small sums of the squares of factor $\mathrm{A}$ is the error factor in ANOVA because the orthogonal arrays matrix does not have sufficient number of experiments. The probabilities of factors $\mathrm{B}$ and $\mathrm{D}$ are satisfied, but the probability of factor $\mathrm{C}$ was not satisfied. Therefore, factors $\mathrm{B}$ and $\mathrm{D}$ were chosen to have the mean of level 3. Factor $\mathrm{C}$ was

Table 8. ANOVA of second orthogonal experimental results.

\begin{tabular}{ccccccc}
\hline \hline Source & DF & Seq SS & Adj SS & Adj MS & F & P \\
\hline B & 2 & 35288 & 35288 & 17644 & 11.20 & 0.082 \\
C & 2 & 4440 & 4440 & 2220 & 1.41 & 0.415 \\
D & 2 & 137329 & 137329 & 68664 & 43.60 & 0.022 \\
\hline Error & 2 & 3149 & 3149 & 1575 & & \\
\hline total & 8 & 180205 & & & & \\
\hline
\end{tabular}

Table 9. Force at initial condition and optimal condition.

\begin{tabular}{cccc}
\hline \hline & Initial condition & Optimal condition & Distinction \\
\hline Force (35A) & $6407.8 \mathrm{~N}$ & $8116.3 \mathrm{~N}$ & $1708.5 \mathrm{~N}$ \\
\hline
\end{tabular}

chosen have the mean of level 1 based on the experimental results. The last optimal design is $\mathrm{A}_{2} \mathrm{~B}_{3} \mathrm{C}_{1} \mathrm{D}_{3}$. Table 9 shows the force at the initial condition and at the Optimal condition.

\section{Conclusion}

This paper describes the optimal design of an air compressor-driving quadratic linear actuator in a fuel cell BOP system using the orthogonal arrays matrix. In the optimal design, the magnetic performance of the linear actuator was improved from that of the linear actuator at the initial condition. All the experiments were carried out at the constraint condition. The number of experiments reduced with the use of the orthogonal array matrix to a total of 21. In addition, the orthogonal array matrix is expected to reduce production costs. The trend of each factor can be predicted by the main effect plot for the means of optimal condition. In the future, the additional research with verified results should be done to evaluate the feasibility of using an air compressor driving linear actuator for the air blower.

\section{Acknowledgement}

Following are results of a study on the "Human Resource Development Center for Economic Region Leading Industry" Project, supported by the Ministry of Education, Science $\&$ Technology (MEST) and the National Research Foundation of Korea (NRF).

\section{References}

[1] K. Y. Lee, A Study on the Shape Optimization Design of the Knuckle using the Orthogonal Array and the Finite Element Analysis, A Master's Dissertation, Dept. of Mechanical Engineering, Graduate School, Dong-A Univ, Busan, Korea (2003).

[2] D. K. Hong, B. C. Woo, and C. W. Ahn, A Study on Performance Improvement of Diaphgram for Micro Speaker using Table of Orthogonal Array, Proceeding of Korean Society for Precision Engineering 2004 Fall Annual Meeting, pp. 298 301 (2004).

[3] Ranjit K. Roy, Design of Experiments using the TAGUCHI Approach, Wiley-Interscience, Hoboken, NJ (2001).

[4] S. H. Park and J. U. Kim, Modern Design of Experiments using MINITAB, Minyoungsa, Seoul (2011). 
[5] J. H. Lee, J. H. Kim, and J. H. Kim, Finite Analysis of the Quadratic Electromagnetic Linear Vibration Actuator, Pro- ceeding of the Korean Society of Mechanical Engineers 2010 Fall Annual Meeting, pp.1278 1282 (2010). 